Bartosz Kałużny*

University of Lodz

\title{
PEOPLE YOU MAY KNOW: HOMOSEXUAL MEN'S IDENTITY IN THE TIME OF SOCIAL NETWORKING SERVICES
}

\begin{abstract}
In the following article several key points are highlighted from a doctoral thesis entitled Gay Men, Social Media and Self-presentation: Managing Identities in Gaydar, Facebook and Beyond written by Elijah M. Cassidy at the University of Technology in Queensland, Australia. The dissertation focuses on the ways in which homosexual men, who use both niche and mainstream Social Network Services (SNS), manage their identities therein. The research uncovers the entanglements of various practices employed in both spaces and presents complex privacy concerns. It also refers to manifold peculiarities of Internet-mediated communication and the ambivalent impact of mainstream and niche SNSs on the sense of collectivity of the researched group. Having presented the main ideas of Cassidy's research I determine the connection between his conclusions and those drawn from two Polish studies which recently treaded the relatively uncharted waters of this research area.
\end{abstract}

Key words: internet-mediated communication, identity, queer studies, social media

My interest in how homosexual users of Social Networking Services shape and manage their identities was sparked by a doctoral dissertation entitled: "Gay men, social media and self-presentation: managing identities in Gaydar, Facebook and beyond" written in 2013 by Elija M. Cassidy at the University of Technology in Queensland, Australia. In my paper I would

* The Department of Transatlantic and Media Studies, Faculty of International and Political Studies, University of Lodz, ul. Lindleya 5a, 90-131 Lodz, e-mail: bartosz.aegee@ gmail.com 
like to take a closer look at this research and consider the relevance of an Australian academic's questions in a Polish context. The following abbreviations will be used in the course of this paper-SNS (Social Networking Service), RL (Real Life, situations which are not Internet-mediated, offline), FB (Facebook) and GD (Gaydar). Having acknowledged the adequacy of the term "research participants" in the case of the Australian qualitative research, due to linguistic aptness I will be using it interchangeably with the term "respondents".

The research question raised by Cassidy was supposed to investigate "how do the cultures and practices surrounding identity management on Gaydar ${ }^{1}$, as an example of an existing, community-specific SNS, fit into the broader ecology of its users' engagements with newer mainstream SNSs, such as Facebook, and their identity management processes in this space" (Cassidy 9). In other words, Cassidy aimed to research how homosexual men between 18-28, living in the city of Brisbane, use two types of SNSs in the process of identity management and what similarities and differences of activities within these two spaces can be observed. In terms of recognizing oneself as a positioned subject Cassidy considers himself an "observant participant" rather than participant observer (Cassidy 2013: 27) since he, just like his respondents, is a homosexual man who used to be a user of both Gaydar and Facebook.

The research employs two main methods of data collection. The first one is participant observation which is mediated through Gaydar profiles (7500 accounts) and various FB profiles and fanpages associated with the gay community in Brisbane (over 50 profiles and fanpages). The observation allowed for the analysis of gay men's self-presentations in both SNSs as well as for investigation of digital infrastructure of FB and GD as the

1 As the author argues Gaydar, the SNS targeted at homosexual men, is extremely popular in most English-speaking countries. It offers two types of membership (a free guest account and a commercial membership account). It was established in 1999 in London and gained its popularity in Australia few years later. Cassidy notices that FB was launched in 2004 and its popularity increased in Australia at the turn of 2007 and 2008 when several magazines commented on social changes brought by this SNS. Thus, some participants had been using GD before they started using FB. In general Cassidy distinguishes two types of SNSs: the niche one (targeted at a specific group of people and revolving around particular interest or activity) and the mainstream one (unspecialized, not aimed at any specific group). Although there are some technical differences between various SNSs, most of them provide similar facilities such as: profiles (private, public or semi-public), contact lists, chats or messengers, photo albums and others. Most SNSs also allow for commenting and sharing various content (such as music, videos etc.) (Cassidy 5; as cited in boyd and Ellison 2007: 2, Albrechtslund 2008: 2, Livingstone 2008: 394). 
environments within which the self-presentations operate. Cassidy examined how users design their presentations in terms of physical aspects, what kind of information users share with others, whether they celebrate or reject markers of gay identity etc. He also analyzed how users present and practice their group affiliations and what modes of interaction they employ. It allowed Cassidy to take into account the specificity of various templates and technical solutions which are offered to SNS users and of which they can take advantage.

In order to cope with the very problematic matter of private and public sphere division in cyberspace Cassidy adopts the perspective of continuum located between two opposite extrema-the public one (available to everyone with no limits, also for non-registered users) and the private one (strictly controlled by the author who precisely manages the visibility of given content and allows selected users to have access to it) (Cassidy 21; as cited in Sveningsson Elm 2009: 135). Cassidy locates SNSs within the semi-public sphere since privacy settings of different users may vary significantly. However, as the unobtrusive observation (which does not require any consent on the part of the observed) was to be carried out, the author needed to cope with the privacy concerns related to such observation. Thus, Cassidy assumes that public sphere for such observation includes spaces which can be accessed by every registered member ${ }^{2}$ of a given SNS (Cassidy 24; as cited in Danet, Ruedenberg-Wright and Rosenbaum-Tamari 1997). The author indicates similarities between such a method of data collection and an offline observation which was employed during the research on nightclubs and shopping centers during the 1990s (Cassidy 24; as cited in Thornton 1996, Lewis 1990).

Another stage of Cassidy's study included individual semi-structured interviews and focus groups (FGI) with the users of both SNSs. Participant observation (site analysis) and individual interviews generated data which suggested questions for further exploration within focus groups. It allowed respondents to comment on the researcher's observation and hypotheses. In order to analyze the generated data Cassidy mobilized discourse analysis and used the QSR Nvivo program. Having analyzed the data he turned to SNSs again and studied profiles and groups within GD and FB, since hypotheses were still to be verified. Overall research which was carried out between 2009 and 2010 included a study of 7500 Gaydar profiles and over 40 Facebook groups and fanpages (related to homosexual men in Brisbane) of that time. A total of 30 respondents (homosexual

\footnotetext{
2 It uncludes a non-commercial membership in GD.
} 
men of different ages living in Brisbane, users of both FB and GD) took part in FGI and interviews.

In the self-reflexive part of his dissertation, the author admits that he used Social Networking Services for several purposes, such as exploring the "gay world" and trying to locate his identity within, following and assisting real-world LGBT events and bonding with peers. He also considered it a source of information and social capital. Cassidy's perspective on SNSs and their complex role in self-presentation inspired the analysis which brought various conclusions.

First, it seems that GD provides digital infrastructure and interface which may strengthen certain stereotypes of homosexual men ${ }^{3}$. The domination of the stereotypical model, from which most respondents distance themselves, leads to isolation and participatory reluctance. The latter is manifested by taking disapproving and dismissing attitudes towards other GD users and GD itself. However, such a negative stance does not stop those who are reluctant from participating in GD life. Reluctant participants consider themselves and their motivations as very different from the dominant ones. According to the respondents Facebook, in comparison to Gaydar, provides greater possibilities for self-presentation and self-expression in less stereotypical ways.

The participants indicated three premises which contribute to their skepticism about GD. Their reasons can be summarized as follows:

nothing but casual sex can be found on GD; GD users are men who are looking for casual sex and who fit squarely into certain stereotypes of homosexual men; there is no real alternative to GD within niche SNSs.

The first reason stems from the participants' perception of GD as a place where they cannot find what they are mainly seeking-a monogamous and long-term relationship (they also quest for gay city guides, flatmates, gym buddies etc.). Most participants consider themselves an exception to the rule. On the one hand, the researched often mobilized the "myth of cyberspace" (Cassidy 85; as cited in Baym 2010) which divides the reality into separate spheres: the offline (the more "real", "important", "normal" or "authentic" one) and online (a kind of substitution for meaningful relations with other people) spheres. Such remarks correspond with the respondents' belief that GD is a place where nothing but casual sex (a superficial substitution of a relationship) can be found.

3 Hedonistic and promiscous white, young, middle-class, homosexual men living in big cities with a strong interest in clubbing and designer clothes (Cassidy 91). 
Furthermore, the very site, like all technologies, is far from ideologically neutral (Cassidy 85; as cited in Akrich, 1992; Latour, 1997; Lessig, 2000). A visit to GD is accompanied by adverts, competitions and various graphic elements which suggest the sexual and "superficial" (respondents' term) character of the site. Though sometimes ads related to LGBT or LGBT-friendly venues can be found, most commercials come from porn sites and have pornographic content. Home page and sign-out screens also include erotic graphics. The profile construction includes explicitly suggestive elements too: the possibility to send naked photographs, indicate penis size, circumcision status, sexual role preference, attitude towards safe sex, fetishes or sexual activities. All those indications appear as key words in a given profile. The very problematic question of fixed categorization and limited possibilities of control over identity performance is increased by menu-driven identities (Nakamura 2002) based on tick-box categories and drop-down menus. Drawing on other scholars' writings (Light, Fletcher and Adams 2008) Cassidy indicates (87) that homosexual men are considered to be less concerned about sex and selling of sex (which is offered in commercial GD membership). However, the group studied seems to contradict this.

Cassidy notices, that respondents' attitudes towards the site and other GD users is a very complex issue which is viciously cyclical. The respondents interact (or not) with other users and evaluate them with lowered expectations. At the same time the group being studied uses their stereotyped attitudes (for instance that GD is not a polite site) to justify their behavior, such as ignoring received messages or negative evaluation of other users on the basis of how they behave (even though the respondents behave in the same or similar way). The illustration of this paradoxical situation is a debate on the parts of profiles which are left blank. The respondents explained that the blank spaces in their profiles were a sign of resistance to the sexualized character of the site. However, when they commented on other users' blank profiles, they concluded that it is because these men use their accounts only to gain access to erotic materials and look for casual sex.

Nonetheless, the respondents' comments on the sexualized character of GD and its users do not seem unjustified. Besides the aforementioned erotic content of the site Cassidy presents some conclusions drawn from the observation and informal talks with older GD users. Older GD members admitted that they are unwilling to connect and stay in touch with the younger GD generation since they tend to chat infinitely and do not seem to strive for a meeting in RL. Older GD users consider such relationships 
a waste of time. In order to explain the generational shift Cassidy provides some wider sociopolitical context.

Taking into account the content of LGBT magazines and publications the Australian scholar concludes that with the passage of time gay identity, which used to be interwoven with political liberation and decriminalization of homosexuality, became more connected to a specific lifestyle and consumption. It seems that gays who became adults in the late $20^{\text {th }}$ century no longer considered LGBT right movements as fundamental to their identity as older generations used to do. A new identity, named by Alan Sinfield (1998) as the metropolitan model, was closely linked to the consumption of particular goods and urban life of white, young, middle-class, homosexual men (Cassidy 91). The ever-expending mass media paved the way for the gay image to be associated with a camp aesthetical style ${ }^{4}$, hedonism, promiscuity, clubbing, drug overuse and love of designer clothes. Its popularity was fueled by the phenomenon of cybercarnality (Cassidy 89; as cited in Mowlabocus 2010: 58) which refers to the pornographic mediation of the gay male body and the fact that for decades it was precisely the gay porn sphere where homosexual relations and practices had been validated and seen as normal. Elsewhere a very heteronormativite attitude towards sexuality had prevailed ${ }^{5}$.

Cassidy fairly argues that since 2004 significant changes can be noticed in mainstream cinematic productions. Movies such as Brokeback Mountain, A Single Man or Beginners present a completely different from the metropolitan model image of homosexual mento wide audiences. Changes can also be observed in public sphere-coming outs which have become increasingly popular amongst famous athletes, movie stars, musicians and TV celebrities. They provide distinct images of homosexual men as they appear on the screen together with their partners and families. The flagship example seems to be Elton John and his husband. As Cassidy's research suggests another of Sinfield's (1998) suppositions that the new, internally diverse post-gay identity will appear in the $21^{\text {st }}$ century was correct. Sinfield claimed that post-gay could not be defined in terms of particular lifestyle, interests, tastes, involvement in political struggle or even the sexual orientation itself.

4 Which in general can be characterized by theatricality, exaggeration, exaltation and ostentation. Camp style is said to be provocative, impudent and somehow disruptive. As Susan Sontag writes (1964): "Many examples of Camp are things which, from a $<<$ serious >> point of view, are either bad art or kitsch".

5 Further explanation of cybercarnality available at: http://vimeo.com/31857570. 
The participants' conviction that GD users strive for nothing but casual sex affects not only their attitude towards the site but also their self-perception. As they employ the mechanism of cognitive simplification ${ }^{6}$ they tend to think of themselves as more normal, more real, more honest and happier than other GD users. The characteristics which respondents attribute to other GD users correspond with those which constitute the metropolitan model. Those in this study group do not wish to be identified with that model since to them it appears unfamiliar and limiting.

Taking the above-mentioned into consideration, the question which remains unanswered is why the participants use GD at all. All respondents, mostly at the age of 18, created their GD accounts since they did not know any other homosexual men (for various reasons such as living in the suburbs, attending boarding schools etc.). Even though the respondents admit that they made some friends via GD and they attended events sponsored by GD they also argue that GD did not provide them with any sense of belonging to a gay community. Facilitated interaction seemed outweighed by "counterproductive" elements of the site (Cassidy 100).

The participants do not publish their naked photos and they ignore sex offers (as well as money-for-sex offers usually sent by older users) they receive. They also declare that having explored several profiles of other users they usually felt discouraged to meet those men in person, for instance during some LGBT events. However, they do not seem to know that the number of young, frustrated and isolated GD users who are looking for a long-term relationship and who distance themselves from the metropolitan model is greater than they might expect. Cassidy claims that it is not necessarily a participants' ignorance or misperception which leads to such a situation. GD's interface imposes limited typology (exemplified by Twink and Bear ${ }^{7}$ categories) which strongly restricts the possibilities of GD users' self-presentations. Then, even if the participants' intention is to leave blank spaces to mark their opposition to fixed categorizations offered by GD, the sexualized character of the site may suggest the wrong interpretation whenever such actions are taken by other users.

Drawing on Judith Butler's idea of performativity (1990) Cassidy notices, that GD users got involved into hitherto existing discourses on gay

6 Which allows for distinguishing oneself from others and creating a positive selfdefinition (Cassidy 96; as cited in Buckingham 2008: 6).

7 These are just two examples of a restrictive typology. Whereas Twink stands for a more "effeminate", young homosexual man who has a slim build and youthful look Bear seems to embody "masculine" traits as he is large, hairy and a bit crude. 
identity. Those discourses which were shaped by previous generations and which became embodied and represented by GD digital infrastructure led to respondents' isolation and frustration. Besides some positive effects were already mentioned, GD does not seem to meet expectations which worked as a motivation for the participants to start using the site. GD does not provide a sense of belonging to some community, neither does it demarginalize respondents' identities (Cassidy 161; as cited in McKenna and Bargh 1998).

When asked about $\mathrm{FB}^{8}$, the respondents took different attitudes and their comments and observations are somehow ambivalent. First, it seems important for the participants that FB does not require from its users any information which is directly related to sexual preferences ${ }^{9}$. In other words, there is no obligation to define oneself in terms of any sexual orientation. The respondents indicate (or not) their preferences and relations with other people in a variety of modes, which seemed to be a very different experience than simple self-definition offered by GD. The participants noticed that even when they indicate their interest in men, the more neutral character of interaction within FB made such indication much less less sexualized. Furthermore, as there is no particular goal or interest on which FB members are focused, the site does not impose any specific "model" of homosexuality. Also, the possibility to set one of many relationship statuses (including 'married' even if it is not legally admissible where a given person resides) extends users' freedom of self-presentation.

During FGI the respondents paid attention to another crucial aspect. Within FB they do not feel defined exclusively through the prism of their sexual orientation and the way they present themselves to the world is more open and changeable. The everyday information which is shared with others, such as movies, music or comments can be interwoven with posts about a night out in a gay club. The homosexual orientation is no

8 It is worth reminding here that FB is the first mainstream SNS which in 2012 was awarded by GLAAD (Gay and Lesbian Alliance Against Defamation) with the Special Recognition Award for its involvement in anti-bullying campaigns and for various efforts to reach an inclusive representation (exemplified by the possibility to set same-sex relationship statuses).

9 Although FB users do not specify their sexual orientation Cassidy received several invitations from companies or institutions which had been previously present on GD as well as from some unknown gay men from all over the world. Moreover, in the 'people you may know' column Cassidy noticed familiar faces he recognized from the local, offline LGBT events. Hence, there seem to be a growing convergence between digital gay culture and mainstream SNSs. 
central issue and it is not precisely framed. The same is true for heteroor bisexuality which makes all these statuses equal. The more neutral FB interface eliminates the conviction that other gay men present on FB are looking for nothing but casual sex. The group studied stopped positioning themselves in opposition to the imagined others and they ceased to consider themselves as more normal or more real. Thus, their feeling of isolation reduced. Also, the equal terms of self-presentations through a stream of information ${ }^{10}$ available for all $\mathrm{FB}$ users allow a more natural narrative to be constructed. Borrowing from Anthony Giddens (1991: 54) Cassidy (106) draws attention to this creative potential which makes "a particular narrative going" and composes a continuous story about a self. In the case of FB the narrative is not sexualized or reduced to restrictive typologies/ stereotypes, which is appreciated by the participants.

Another important remark on FB is that the general transparency and lack of anonymity within the site increases users' authenticity and strengthens the conviction that their self-presentations correspond with who they are in $\mathrm{RL}^{11}$. According to the participants, the very popular practice is to leave in GD a notice about the FB profile (for instance by sharing an e-mail address) so that a given user can find one on FB. In this way the participants avoid inscribing themselves into the restrictive GD template. Also, due to the wider stream of information ${ }^{12} \mathrm{FB}$ allows for compatibility verification and facilitates the selection of people with whom the respondents would like to stay in contact. Looking through somebody's friends list seems to be a useful source of information. Not only does it suggest what kind of person one is but also some more or less complicated relations with other people can be noticed (as Cassidy argues [133] somebody's "history" is of utmost importance for minority groups residing in smaller

${ }^{10}$ Which includes posting various remarks, liking, commenting, partaking in different events [LGBT ones too], joining interest groups and many others.

${ }^{11}$ On the one hand, self-presentations in online spaces are rarely honest (Cassidy 42; as cited in Baym 2010: 121). However, Cassidy fairly notices (42) that the debate over authenticity leads to the question of anonymity seen as disembodiment and liberation from stigmatized identities (as for disabled people) or demarginalization of identities (McKenna \& Bargh 1998, Morahan-Martin 1999, Tyler 2002, McIntosh and Harwood 2002). The more pessimistic vision of online anonymity suggests the possibility of social isolation and problems with the interaction in RL (Cassidy 42; as cited in Kiesler, Siegel and McGuire 1984, Beninger 1987, Parks and Floyd 1996).

${ }^{12}$ One participant provided an example of information about religious and political beliefs. Although there is a possibility to reveal one's religious and political beliefs in GD the participant argues that FB allows to learn more about somebody's attitudes due to the variety of information shared. 
areas). Checking a FB profile which belongs to somebody the respondents know from GD and screening one's friends serves as a "virtual compass" (Cassidy 130; as cited in Donath and boyd 2004). It helps avoid interaction with those whom the participants cannot tolerate as their friends.

The wide variety of information which can be shared on FB is considered by the participants as a huge advantage ${ }^{13}$. However, Cassidy (125) borrows from Fiske and Taylor (1984) and their concept of cognitive miser ${ }^{14}$ and draw on some research (Ellison, Heino and Gibbsa 2006) which indicates that in technologically-mediated environments cognitive misery is heavily increased when compared with offline milieu. In the case of SNS (Cassidy 126; as cited in Baym 2010: 119) the very fragmented information (particular photos, quotes, shared interests etc.) are used to fill the blanks in our knowledge about other users. Consequently such simplified images are built upon social cues which are very distinct from those processed in face-to-face interaction. Such phenomena are present despite the amplified range of information shared on FB.

Still, it seems that FB plays an important role in reducing participants' sense of isolation through interaction with other homosexual users who join particular LGBT-friendly places, events or interest groups. The respondents were almost unanimous in their claims about contacting other like-minded gay men with similar interests. They argued that these relations were just normal and fit their way of living ${ }^{15}$. Cassidy notices that becoming members of various groups, partaking in different events and general interaction within FB is not experienced by the group studied as belonging to the gay community but to the "normal" or "open" one. Their resistance to the metropolitan model offered by GD appears even more explicitly here.

The conclusions drawn from the observation of local LGBT groups on FB correspond with respondents' critical comments on GD. Those groups

${ }^{13}$ Cassidy (124) indicates that the self-disclosure, which is possible on FB, is connected with what Caroline Haythornthwaite (2005) calls media multiplexity (MM). MM stands for people's tendency to employ more media in relationships as people grow closer. That is another reason why it is FB and not GD, which is used by the respondents to maintain the acquaintances made offline.

${ }^{14}$ This term refers to people's tendency to use mental shortcuts and minimize their cognititive effort while making sense of the world around. Because of efficiency reasons people employ the least complicated (and not the most accurate) approach in order to solve a provlem. As a result huge volumes of information are extrapolated on the basis of minimal social cues.

${ }^{15}$ For instance, one respondent used FB to find and join a local LGBT swimming squad. 
which revolve around sexual orientation itself (such as "Gay Brisbane") are less active and less numerous in comparison to groups associated with various activities or hobbies. Moreover, at the time of observation out of 133 members of "Brisbane Gay Men's Facebook Chat Group" 126 users were over 30 years old which confirms respondents' (who were between 18 and 28 years old) claims that their attitude towards sexuality and its role in identity formation is connected with generational shift. The participants were eager to join groups associated with various events and interests associated with LGBT people ${ }^{16}$ rather than groups which just gather homosexual people.

The question concerning the future existence and usefulness of such sites as GD in the present form evoked discrepant opinions. Participants debated whether GD (as a necessary evil) is indispensable for young gays to become familiar with some part of gay culture (even if they reject it) or it is detrimental as it strengthens the domination of the metropolitan model. The general conclusion drawn was that the advent of mainstream SNS, which are not targeted at any specific group of people, enables the users to present themselves in a more unrestricted manner and thus makes younger generations more critical about GD-like sites.

As Cassidy underlines, privacy concerns and identity management are inseparably linked. Keeping the balance between the information which is revealed and concealed is central to identity formation (Cassidy 145; as cited in Goffman 1959, Schlenker 1980, Baym 2010, Quercia et al. 2012). The decision about a disclosure of particular information lies at the very heart of various relationships (Cassidy 145; as cited in Altman and Taylor 1973, Chan and Cheng 2004) and lets distinct roles to be taken on in different interactions. Naturally, what is considered private is socially negotiable and depends on a wide spectrum of factors and circumstances such as historical context and social expectations (Cassidy 145; as cited in Prost et al. 1991) affected by race, sexual orientation, social status, religious beliefs and many others (Cassidy 145; see more: Gilbert, Karahalios and Sandvig 2008, Chang et al. 2010, Quercia et al. 2012, Tufekci 2012).

To draw a line between various contexts or types of interaction in RL seems easier than to do it in cyberspace. Online communication mediated by SNS is constantly endangered by context collapse (Cassidy 13; as cited in Hogan 2010, Marwick and boyd 2011) and privacy trainwreck (Cassidy 48; as cited in boyd 2008) since the users need to face the fact that the information they share can be re-shared, commented and received in very different con-

${ }^{16}$ For instance "Top the Chef: Gay Cooking Club" (Cassidy 121). 
texts in real-time. The awareness of what the norms of a given interaction are and who participates in the interactional situation in cyberspace is low$\mathrm{er}^{17}$ and so is the accuracy of measures employed. The successful interaction requires not only participants' awareness of this fact but also their technological literacy (Cassidy 146; as cited in boyd and Hargittai 2010) which allows for the proper management of privacy settings and information visibility.

Cassidy argues that GD privacy arrangements are simple, stable, intuitive and user friendly. GD privacy policy includes regulations of account privacy (external access to the profile, its visibility in search engines, visit tracking), protection against unauthorized use of private content (picture watermarking), LGBT-friendly police, options to block a given user from one's account and many others. Whether one prefers full transparency (with profile's visibility in search engines and one's real name ${ }^{18}$ ) or invisibility, the accessibility to all functions offered by GD remains the same (the same functions are also available to the users who have no friends added or are not members of any groups).

For most respondents the chance to recognize somebody offline (during different events) who they already knew from GD improves their comfort and confidence as the site users. Often the reversed situationdiscovering that somebody respondents knew in person was present on GD-was a catalyst in relationships (particularly those with neighbors, flatmates or colleagues). Another positive aspect is a facilitated interaction online after even the most coincidental encounter offline and vice versa. In both cases the initiation of conversation was easier. Moreover, in spite of the negative opinion on GD in general, one of the respondents argued that his sense of isolation reduced significantly after he had discovered that there are so many homosexual men living in Brisbane (it is worth noticing that discovering the very number of homosexual men living in Brisbane does not translate into positive evaluation of these people).

Several privacy concerns refer to offline encounters with GD users with whom the participants only had online contact. The respondents highlight non-gay contexts, such as a chance meeting in a store during work. Some better or worse relations which stem from previous online interaction seem to be valid only in that specific context and cannot be easily transferred into the offline situation between a customer and a shop assistant. The participants also draw attention to the impression they could

\footnotetext{
${ }^{17}$ In comparison with offline situations. Face-to-face interaction is usually limited to a specific audience and takes place in a given space.

${ }^{18}$ Which is not required.
} 
not dispose of and which made them feel uncomfortable. They tended to create negative images of GD users on the basis of what they had observed online and could not change such unfavorable perception while seeing these people offline.

On the other hand, Facebook privacy concerns are far more complex. Cassidy elaborates on multiplicity of options and extended regulations. He also notices that for an ordinary user it can be really time-consuming to become familiar with all the details of constantly changing privacy policies (default settings after each change do not provide the highest privacy protection). FB's insistence on transparency with its requirement of real-name profiles (successfully circumvented by some users) appears as a place where users are encouraged to reveal as much information as possible. Such elements of digital infrastructure as the Timeline which is expected to present the story of a lifetime or various applications which summarize specific periods of users' life are quite suggestive examples.

By offering and somehow imposing such transparency and openness, Facebook subscribes to a "nothing to hide, nothing to fear" style of rhetoric. It divides people into those who may be afraid to freely express themselves in some contexts and those who have no (or little) reason to fear. It does not come as a surprise that the respondents have their doubts about the policy which is conducive to context collapse. Reduced control over the shared information increases the possibility of being received by audiences which are not the addressee. Drawing on other scholars' writings (Cassidy 167; as cited in Hogan 2011, boyd 2011) Cassidy also notices that the potential decontextualization ${ }^{19}$ somehow violates the right to free speech which is context-specific ${ }^{20}$.

In general, privacy concerns related to $\mathrm{FB}$ are definitely much greater. One of the most troublesome questions is the possibility that the information shared within FB can reach close family (and not some unknown people as in the case of GD) to whom it is not addressed (Cassidy 169; as cited in Livingstone 2008). The researched were concerned about the unwanted mixing of information on their orientation with those from professional, domestic and other spheres. Even those participants who openly identified themselves as gay in all possible contexts did not want their homosexuality to be "rubbed in the face" of their families (Cassidy 170).

\footnotetext{
${ }^{19}$ Which can happen when the information is re-shared or shared with new (or edited) comments added.

${ }^{20}$ Since people are free to say what they want to the audience they chose and in the specified situation they are aware of.
} 
Due to participants' inability to control all the information via privacy settings, some of them resort to self-censorship whereas others rely on the idea which resembles Goffman's civil inattention (Cassidy 170; as cited in Goffman 1963). In other words, they assume that some gay-oriented content they share would be ignored or misunderstood by those to whom the information is not addressed. However, those participants who could not count on civil inattentiveness (since, for some reasons, they could not come out to all possible audiences at a particular moment) employed alternative strategies for protecting their privacy.

The most popular tactic seems to be the limitation of FB friends (realized in many different ways-by the upper limit, personal/offline acquaintance, probation period, according to common interests etc.). Some participants create special codes for their gay friends or gay locations (so that they could be understood only by specific audiences). As Cassidy notices (172) coding, as a method based on social knowledge and not on structural access, has been also noticed by other researchers (Marwick and boyd 2011: 2) who studied the usage of SNS by teenagers and parental surveillance. Another tactic is "lagging" (sharing information about different activities with such delay that people who live in the respondent's hometown cannot keep track of his life), untagging photos from LGBT events or deleting suggestive comments. One of the respondents decided to only post such information which he considered proper to be viewed by all SNS members, which Cassidy calls (Cassidy 173; as cited in Hogan 2010) the lowest common denominator approach.

Cassidy notices further negative implications of FB transparency for the researched group. Some self-restrictions which respondents impose limit their access both to online socializing (when they stop being members of some LGBT groups due to the possible leak of such information) and offline integration (when they stop attending offline LGBT events due to the possible leak of photos and the unsolicited linking to one's FB profile). The phenomenon of facestalking (undesirable following and monitoring somebody's profile on FB often connected with intimidation or harassment) was also mentioned as a serious privacy concern for those who use simultaneously FB and GD.

It seemed that some of the participants' privacy concerns are quite justified. Out of 30 respondents 3 were outed ${ }^{21}$ to their families via FB, which caused family conflicts. The participants also indicated offline stalking

${ }^{21}$ When a person is outed it means that one has been discovered as a homosexual without one's persmission or intention. 
(which can be facilitated by FB transparency) as particularly threatening due to the relative low number of homosexual men in Brisbane and few physical places (which along with events can be traced online) where they meet.

What seems important for further SNSs analysis is the fact that the participants (despite the employment of various preventive measures) do not appreciate the very basic features of information located in cyberspace. Drawing on other scholars' writings (Marwick and Boyd 2011: 9) Cassidy (177) itemizes four important properties of such information:

- persistence

- replicability

- scalability

- searchability

All these properties have a significant influence on the users' safety, specifically when users are not too familiar with how to configure their privacy settings. The flagship example are pictures from LGBT events which in pre-SNS era (or even before the Internet gained such popularity) appeared in paper magazines ${ }^{22}$ targeted and usually read by a specific audience. It was not possible to multiply the materials infinitely and at the great speed or seek them in real time with the help of search algorithms. The control over information on FB is also weakened since the re-sharing destabilizes its placement. As a result, pictures from a local gay club in Brisbane appear not only to those who look through the fanpage but also to those who follow it (as they receive a notice in their newsfeed) or those who are tagged in the photos ${ }^{23}$. It is also seen by friends of the user who are not in the photo but simply shared it.

When it comes to comparison of privacy concerns related to FB and $\mathrm{GD}$, the former evokes definitely more doubts. Facebook as a space where the information can be shared and re-shared, commented, multiplied,

${ }^{22}$ Instead of 400-500 digital pictures which circulate in the web out of control in various contexts there were $4-5$ photos in a given issue.

${ }^{23}$ It is worth noticing that whether a given user requires to check and accept tags before they appear on one's timeline or not they are visible in the SNS anyway. When some of our friends recognize us in the photo and tags us in the comment, this comment redirects others to our profile. Sometimes several comments start a whole discussion which could be followed both by friends of the users tagged in the photo (or in the comments) and by those who follow a given fanpage or simply look through it. After several re-sharings the photo together with the comments which accompany it can appear completely out of context. The user who is in the photo can be unaware of a potential homophobic bulling until he or she logs in FB (and reads a notification) or discovers the photo oneself. 
received in various contexts by unknown audiences which makes the interactional situation somehow unpredictable and results in context collapse. Due to the growing popularity of FB and its expanding outreach more and more people use this SNS as their regular work tool which complicates the matters even more. On the other hand, less abstruse privacy settings and no real-name policy in GD results in minor concerns. The possible identification of a GD user is usually connected with two negative phenomena ${ }^{24}$ : one's homosexuality is revealed (those users who did not come out in all spheres of life) or/and one is inscribed into the metropolitan model (those users who came out but do not wish to be identified with such a model).

Apart from privacy and safety concerns related to each SNS the respondents indicate some interconnections between FB and GD in terms of both safety and functionality. The majority of participants (27 out of 30) claimed they use simultaneously both SNSs due to practical reasons. They initially search for other homosexual men in GD and then they turn to FB to gain more information on that user (for instance by using one's e-mail address). Such a strategy, as reported by respondents, often helps avoid "dramas" 25 (Cassidy 183). Sometimes, using FB, they also follow places and events, wherein a given user declares to appear, and arrange encounters. However, in a reversed situation the respondents express serious concerns about such facestalking.

On the other side, before the advent of FB, GD users could only be recognized by some skillful observer from GD. FB allows you to not only finda user's real name but also to discover a lot more or less personal information which is circulating within the SNS. It discourages GD users from setting their faces in profile pictures or from using FB or MSN as communicators ${ }^{26}$. The latter practice used to be a regular one not only because of ideological reasons (trying to keep off of GD as much as possible) but also because of technical premises. The chat offered by GD is said to be problematic for the non-commercial user.

While drawing more general conclusions Cassidy (192) quotes Kris Schmidt (2011), the gay blogger who argued that "no one has benefited more socially from the Internet than the gays. The Internet opened up an entire world to let gay people know we're not alone; that there is hope

${ }^{24}$ Gaydar is used mainly by other homosexual men, hence the possibility of homophobic bullying or purposeful spread of orientation-related information is more unlikely. The amount of personal data and the opportunity to trace someone is very limited in comparison to $\mathrm{FB}$, therefore the danger of stalking is reduced too.

${ }^{25}$ The engagement into unworthy relations.

${ }^{26}$ MSN reveals user's e-mail address which can be used to search for more information in FB. 
and help out there; and that you're perfect just the way you are". Referring to the Australian research (Hillier, Kurdas and Horsely 2001) Cassidy (12) underlines that chats used to play an important role in homosexual youth's lives. Interaction with like-minded others, facilitation of offline relations with same-sex-attracted young people, reduction of a sense of isolation, provision of a sense of community and safe spaces for discussion are just some of the benefits of chats. Thus, the very fact that the participants in Cassidy's research indicated several privacy concerns seems important not only due to the long history of LGBT people's engagement in social media and Internet communication. It seems also significant since this demographic is considered to be skilled at identity management and equilibration of disclosure and concealment of personal information in various contexts, also those technologically-mediated (Cassidy 188; see more: Gross 2007: vii-x).

However, the role of SNS in gay digital culture is crucial not only because this demographic has been long involved in SNSs usage or due to the groundbreaking opportunities to interact with other non-heteronormative people provided by SNSs and Internet communication. It is also the struggle for the legalization of same-sex-marriages, combating stereotypes and counteracting against homophobic bullying which is carried out within places such as FB, Twitter or Youtube. The SNSs' contribution to the reduction of homophobic bullying will be commented in the further part of this article.

Cassidy's dissertation provides rich, qualitative data which reveals various motivations, strategies and dilemmas connected with identity management in two different SNSs. The study becomes an important source of knowledge not only for academics but also for SNS and other digital space designers. As the research was focused mainly on FB and GD some questions related to other SNSs, such as Grindr or Hornet were not elaborated upon. Undoubtedly, respondents' remarks encourage further explorations in this direction.

Also, taking into account LGBT youth's higher level of anxiety and depression (Cassidy 194; as cited in Leonard et al. 2012) as well as a higher rate of suicidal thoughts and behaviors ${ }^{27}$ (Cassidy 194; as cited in National LGBTI Health Alliance 2010, Suicide Prevention Australia 2009: 20) the study seems to be a source of key information on privacy concerns, fear of homophobic bullying or a sense of collective belonging and isolation. The latter respondents experienced this within a part of the LGBT community

${ }^{27}$ In comparison to the heteronormative youth. 
rather than outside of it (Cassidy 194). Such observation can be crucial for LGBT organizations which cope with matters of mental health.

The study provokes further questions about the anxiety and its intensity when it comes to disclosure or concealment of sexual orientation of those non-heteronormative SNS users who are closeted or partially out. Cassidy underlines, that not all participants, who were out in every possible context, approved of FB full transparency. It seems that a different degree of users' sensitivity to unwitting outings and their vulnerability to such situations is of a very complex nature. The identification and examination of various factors and contexts which can increase the users' anxiety, such as specificity of a given workplace or friends' beliefs and ideological convictions may contribute to the modification of SNSs policy as well as to wider social changes.

The generational shift which seems to have taken place among homosexual men is another important aspect of Cassidy's research. Fear of being perceived through the prism of specific stereotypes, the opposition to sexualization and the metropolitan model as well as the wish for normalization ${ }^{28}$ indicate an important change which was brought by the new generation. Cassidy's conclusions are not based solely on his research. He underlines that the necessity for redefinition of gay identity was publicly highlighted in 2012, when the founder of Hello Mr. magazine, Ryan Fitzgibbon, wrote about the misrepresentation of homosexual men (Cassidy 196; as cited in Fitzgibbon 2012). This shift is related to the new generation's distinct experience of gay history and culture since particular problems, values and priorities of previous generations have been replaced by new ones. Such a problem might be solved with LGBT organizations' further efforts to promote variety and less restrictive identity models. It could decrease a sense of isolation and respondents' feelings of inadequacy (as Cassidy underlines the participants' sense of isolation did not stem exclusively from the discovery of being homosexual but from the lack of correspondence between their behaviors, attitudes and longings and the dominant metropolitan model).

Finally, the research draws attention to the growing role of SNSs in identity management in general, not only for non-heteronormative users. Cassidy draws attention to the growing pressure to partake in SNS life and all users' need to face privacy breach and context collapse. The online environment with its constantly expanding options, novel techno-

${ }^{28}$ Achieved through the increased diversity of homosexual men representation which finally leads to the equalization of various orientations. 
logical solutions and changing goals is where identities are being shaped to a higher extent (Cassidy 191; as cited in James et al. 2008: 15). The interdependent and colliding practices of identity management in different online spaces are likely to play an increasingly important role.

Bearing in mind the relevance of the Australian research it seems that the current state of LGBT studies and digital culture studies in Poland suggests the increased demand for common efforts aimed at developing interdisciplinary projects of this kind. As the literature review lies beyond the scope of this article my intention is to refer to some Polish research which cope with similar matters and to comment on the possibilities of further explorations. In recent years dynamic developments of Polish studies in digital culture and its various aspects can be noticed. Within the field of digital culture one can find research which corresponds with Cassidy's study. The results of the first one are presented in a paper entitled "Connecting to reality-Polish gays in the Internet/Polscy geje $\mathrm{w}$ internecie" (2006). The study was carried out by Marta Klimowicz from the University of Wroclaw. The results of the second study are presented in the article entitled "The influence of the Internet on relations in groups of homosexual men in the city of Torun/Wpływ internetu na relacje w grupie osób homoseksualnych w Toruniu" (Lewandowski \& Kobylska 2011). The research was undertaken by a group of students from the Nicolas Copernicus University in Torun. Even though both studies are analytically less advanced in comparison with Cassidy's full doctoral dissertation, they set an interesting direction for further exploration.

The Torunian research, just like the Australian one, examined two types of data: the content of SNSs and in-depth interviews with eleven homosexual men (of different age) from Torun. The report presents remarks on the impact of digital and web environment on relationships among Torunian gays, which means it is not focused exclusively on SNSs. Klimowicz also analyzed two types of data: the content of gay blogs and sites (she employed both qualitative and quantitative measures) as well as standarized interviews and replies to queries posted on gay forums. Thus, her study does not analyze SNS directly as she focused on a kind of online collectivity which is constituted by homosexual men in Poland and on a role which virtual spaces play in their lives. On the other side, the Torunian project (which draws on Klimowicz's study) aimed to explore how the Internet affects homosexual men on a collective and individual level and in terms of internal communication. Both studies share an interest in interrelations between offline and online interactions of homosexual men. 
While writing about this field of research in Poland and Australia it is worth commenting on some sociopolitical circumstances which are common for both places. First, there was little or no positive representation of homosexual men in the mainstream media in the period before 1990 . Despite the fact that officially homosexuality ceased to be penalized in Poland in 1932, it was still persecuted during the communist period. Any official and open LGBT activity was hampered and the very question of non-heteronormative people situation became marginalized (the authorities' refusal of official recognition of the Warsaw Gay Movement in late 1980s, the Operation Hyacinth and others). In Queensland homosexuality was decriminalized in 1990 (Cassidy 72) which suggests the specificity of LGBT people's situation beforehand. Cassidy comments (72) on governments' endeavors to block any consolidation of LGBT milieu. The sociopolitical atmosphere in Poland and Australia before 1990 resulted in homosexual people's invisibility on one hand and to their consolidation (paradoxically, as counter-reaction) on the other.

The very brief description of the Torunian environment of homosexual men and its transformations brings into perspective the changes brought on by the advent of the Internet. The authors start with an overview of the pre-1989 period when informal (and illegal) gay gatherings/cruisings (Pol. pikiety) were a popular form of contact with other gays. Relations started during such meetings and were usually passing acquaintances of a sexual character. Any information about meetings circulated within narrow circles and was confidential. The period after 1989 was the time when the first gay bars and clubs appeared ${ }^{29}$. Also, the first official LGBT organizations and magazines ${ }^{30}$ were founded. The changing situation increased group consciousness and boosted the development of symbolic communication and linguistic metaphors (Lewandowski \& Kobylska 201). It also reduced anonymity. The sources of gay identity were to be found in personal interactions with other homosexual men but also in official publications on LGBT matters. The role of stereotypes and heteronormative knowledge started to be diminished. However, as Klimowicz fairly argues (308) the representation of homosexual men in Polish media was (and still is) scarce and biased when compared with, for instance, American discourse.

${ }^{29}$ The research describes Torunian reality of that time. Generally in Poland before 1989 pubs in which homosexual men were gathering existed in disguise. The informal gay pubs are referred to by Krzysztof Tomasik in his book Gejerel. Sexual minorities in the People's Republic of Poland/Gejerel. Mniejszości seksualne w PRL-u (2012).

${ }^{30}$ The situation was similar in Queensland where the very first local LGBT publication, Queensland Pride, was issued in 1991 (Cassidy 72). 
The identity formation, as inextricably linked to the accessibility of information, was therefore significantly affected by the advent of new media $^{31}$. Both Polish (Lewandowski \& Kobylska 202) and Australian (Cassidy 159) studies reveal that new media and web communication significantly increased group consciousness and LGBT people's interaction. Cyberspace permits secure and comfortable searches for various content and facilitates the exchange of experiences and interaction with like-minded people. Cyberspace also affects the coming-out process and speeds it up (Lewandowski \& Kobylska 211). Klimowicz (317) underlines that gay blogging also reduces the sense of isolation and loneliness due to the free exchange of experiences and thoughts. The information shared by other users (via forums, blogs or other spaces) provides a base for the negotiation of behavioral patterns, norms or solutions to interactional pitfalls (321). Thus, further studies on sexual minorities' identity formation and digital, web-based environment appear extremely necessary.

One of the most interesting of Klimowicz's conclusions is that in spite of the increased LGBT-related content in traditional media (for instance the growing number of cover stories on LGBT matters in mainstream magazines, see more: Oliwa 2012: 113) cyberspace is considered to be more representative of reality than the offline world. Moreover, the respondents argue that initiating a long-term relationship on the Internet is perfectly normal and valuable. Besides, they believe that cyberspace allows the tightening of the relation and getting to know the other party better (Klimowicz 320). It stays in partial but apparent contradiction with the Australian research (Cassidy 85) where the aforementioned myth of cyberspace was alive ${ }^{32}$.

On the other side, the advent of the Internet and new media led to a kind of disintegration of the Torunian group of homosexual men. It seems that such disintegration overlaps with Cassidy's conclusion since the extension and dispersion of young homosexual men's identities was sparked in both groups. The participants do not feel obliged to adopt, for instance, the metropolitan model. Also, they do not consider being homosexual men as inseparably connected with partaking in cruising, going

${ }^{31}$ Beforehand this information was much more limited. The scarce and biased representation of homosexual men in the mainstream media and growing, but still limited, interaction of Torunian gays prevailed.

${ }^{32}$ As the myth of cyberspace was mobilized only in the context of Gaydar it cannot be extended over the whole online environment. 
out to gay bars or being engaged in political struggle. Internet-mediated interaction allowed young men to define themselves as gays on different terms (Lewandowski \& Kobylska 202). The growing diversity and emerging subgroups (revolving around various interests, ways of life etc.) are parts of the same process within which the resistance to the metropolitan model is located. The experiences of isolation and the growing diversity of gay identity in Poland promotes further examination.

Attention should also be paid to the question of anonymity, which according to Torunian authors (Lewandowski \& Kobylska 205) is highly appreciated by the respondents and motivates them to use niche SNSs for gays. Does the anonymity affect these users' involvement in mainstream SNSs? Do gay SNS users consider transparency disturbing or useful in reducing homophobic bullying and hate speech? What are the interrelations between using mainstream and gay SNSs in the Polish context? How does the specific sociopolitical context influence the participation in online communities? ${ }^{33}$.

I believe that a comparative research which explores how two demographics (different generations of homosexual men with similar sociometric parameters) manage their identities online while using SNSs (both niche and mainstream ones) could be realized with mixed methods of data collection and analysis (such as content analysis of secondary data available online and multiple FGI or IDI with subjects of both demographics). Such research could reveal how different generations of homosexual men are affected by the growing participation in SNS and the increasing importance of online spaces.

Urgent questions which could be studied within such projects are privacy concerns (specifically those related to coming outs) and the diversification of gay identity. The research would also provide some clues about SNSs' role in promoting equality. Finally, it could be verified how the Parasocial Contact Hypothesis (PCH) resonates with the presence of

${ }^{33}$ Polish context seems specific for at least two reasons. First, the history of mainstream SNS usage is relatively shorter and has its peculiarities. Second, two main Polish gay-targeted SNSs (Kumpello and Fellow) seem less sexualized when analized in the manner employed by Cassidy. One of the first options offered to newcomers in Kumpello is the possibility to set a filter on sexually offensive content. Neutral ads (bookstores, banks) can be noticed in the background. The site offers various interest groups or place-related groups. Fellow seems to be more sexualized-there can be noticed half-naked models in the background, however, the pictures cannot be labeled as pornographic or even erotic since they could be easily presented on Men's Health cover. Fellow also offers a more extended template of sexual preferences. 
non-heteronormative people in mainstream $\mathrm{SNSs}^{34}$. Cassidy (69) pays some attention to $\mathrm{PCH}$ while noticing that common interests, friends or places visited can build positive relations and reduce homophobic bias ${ }^{35}$. The variety of information shared via FB and the multifaceted interaction in the site (for instance hetero- and non-heteronormative users' participation in the same interest group etc.) can be seen as a kind of parasocial contact and may reduce the homophobic bias or facilitate mutual understanding of heteronormative and non-heteronormative users. It can also normalize their interactions by making sexual orientation a non-issue. In order to gain better answers to such questions it would require engaging both homosexual and heterosexual respondents.

Generational differences seem to have various implications, ranging from technological literacy, through to distinct sociopolitical (or socio historical) experiences, ending up with a variety of problematic coming outs. The latter issue seems particularly important for those men who stayed in the closet for several years (sometimes decades) because of unfavorable circumstances of the past which had shaped their family or professional situations (Lewandowski \& Kobylska 214). Contrasting participants for whom SNSs and online interaction are inseparably linked with their lives (and thus play a naturally greater role) with homosexual men whose identities were also being shaped in the pre-Internet era would provide a more holistic image of this still relatively unexplored field of research.

\section{Bibliography}

Akrich Madeline 1992, The De-scription of Technical Objects, [in:] Shaping Technology/building Society: Studies in Sociotechnical Change, eds. W. Bijker and J. Law, Cambridge (MA): MIT Press.

Albrechtslund Anders 2008, “Online Social Networking as Participatory Surveillance", First Monday No. 13(3).

${ }^{34} \mathrm{PCH}$ aasumes that the indirect/mediated contact with positive images of minorities can result in bias reduction. In practice $\mathrm{PCH}$ could be verified, for instance, by tracing the influence of the positive representation of Tomasz Raczek (Polish film critic and journalist who, together with his partner, was awarded Gala Roses 2008 for the most beautiful couple of the year) on the mitigation of homophobic attitudes.

${ }^{35}$ In terms of $\mathrm{PCH}$ it seems that due to the basic properties of Internet communication the information can be considered as more "real" or les ideologically burdened (no central distribution of information, the possibility to post critical comments and to share information freely etc.). 
Altman Irwin, Taylor Dalmas 1973, Social Penetration: The Development of Interpersonal Relationships, New York: Holt.

Baym Nancy K. 2010, Personal Connections in the Digital Age, Malden (MA): Polity.

Beninger James R. 1987, "Personalization of Mass Media and the Growth of Pseudocommunity", Communication Research, No. 14.

boyd danah 2008, “Facebook's Privacy Trainwreck: Exposure, Invasion, and Social Convergence", Convergence, No. 14(1).

boyd danah, Ellison Nicole B. 2007, "Social Network Sites: Definition, History, and Scholarship", Journal of Computer-Mediated Communication, No. 13(1): http://jcmc.indiana. edu/vol13/issue1/boyd.ellison.html

boyd danah, Hargittai Eszter 2010, “Facebook Privacy Settings: Who cares?”, First Monday, No. 15(8).

boyd danah, Marwick Alice 2011, Social Privacy in Networked Publics: Teens' Attitudes, Practices, and Strategies, paper presented on $22^{\text {nd }}$ August during the Oxford Internet Institute Decade in Internet Time Symposium, available at: http://www.danah.org/papers/2011/SocialPrivacyPLSC-Draft.pdf.

Buckingham David 2008, Introducing Identity, [in:] Youth, Identity, and Digital Media, Cambridge MA: The MIT Press.

Butler Judith 1990, Gender Trouble: Feminism and the Subversion of Identity, New York: Routledge.

Cassidy Elija M. 2013, Gay Men, Social media and Self-presentation: Managing Identities in Gaydar, Facebook and Beyond, doctoral dissertation written at Queensland University of Technology, available at: http://eprints.qut.edu.au/61773/

Chan Darius K. S, Cheng Grand H. L. 2004, "A Comparison of Offline and Online Friendship Qualities at Different Stages of Relationship Development", Journal of Personal and Social Relationships, No. 21(3).

Danet Brenda., Ruedenberg-Wright Lucia, Rosenbaum-Tamari Yehudit 1997, “'Hmmm... Where's That Smoke Coming From?'. Writing, Play and Performance on Internet Relay Chat, Journal of Computer-Mediated Communication, No. 2(4).

Donath Judith, boyd danah 2004, "Public Displays of Vonnection", BT Technology Journal, No. 22(4).

Ellison Nicole, Heino Rebecca, Gibbs Jennifer 2006, “Managing Impressions Online: Selfpresentation Processes in the Online Dating Environment", Journal of Computer-Mediated Communication, NO. 11(2), available at: http://jcmc.indiana.edu/vol11/issue2/ ellison.html

Fiske Susan, Taylor Shelley 1984, Social Cognition, Boston (MA): Addison-Wesley.

Fitzgibbon Ryan 2012, "About the Magazine", HelloMr., available at: http://hellomrmag.com.

Giddens Anthony 1991, Modernity and Self-Identity: Self and Society in the Late Modern Age, Stanford: Stanford University Press.

Goffman Erving 1959, The Presentation of Self in Everyday Life, Carden City, N.Y.: Doubleday Anchor.

Goffman Erving 1963, Behaviour in Public Places: Notes on the Social Organization of Gatherings, New York: Free Press. 
Gross Larry 2007, Foreword, [in:] Queer Online: Media, Technology and Sexuality, eds. K. O’Riordan, D. J. Phillips, New York: Peter Lang.

Haythornthwaite Caroline 2005, "Social Networks and Internet Connectivity Effects", Information, Communication and Society, No. 8(2).

Hillier Lynne, Kurdas Chyloe, Horsley Philomena 2001, 'It's just easier': the Internet as a safety-Net for same sex attracted young people, Melbourne: Australian Research Centre in Sex Health and Society, La Trobe University, available at: http://apo.org.au/node/15390

Hogan Bernie 2011, Real Name Sites Are Necessarily Inadequate for Free Speech, post from 08.08, available at: http://people.oii.ox.ac.uk/hogan/

Hogan Bernie 2010, "The Presentation of Self in the Age of Social Media: Distinguishing Performances and Exhibitions Online", Bulletin of Science, Technology and Society, No. 30(6).

Kiesler Sara, Siegel Jane, McGuire Timothy W. 1984, "Social Psychological Aspects of Computer-mediated Communication", American Psychologist, No. 39(10).

Klimowicz Marta 2006, Connecting to reality - polscy geje w internecie, [in:] Re: Internet - społeczne aspekty medium, eds. Ł. Jonak, P. Mazurek, M. Olcoń, A. Przybyłska, A. Tarkowski, J. M. Zając, Warszawa: Wydawnictwa Akademickie i Profesjonalne.

Latour Bruno 1997, Aramis, or the love of technology, London: Routledge.

Leonard William, Pitts Marian, Mitchell Anne, Lyons Anthony, Smith Anthony, Patel Sunil, Couch Murray, Barrett Anna 2012, "Private Lives 2: The Second National Survey of the Health and Wellbeing of Gay, Lesbian, Bisexual and Transgender (GLBT) Australians", Monograph Series, No. 86, Melbourne: The Australian Research Centre in Sex, Health and Society, La Trobe University, available at: http://www.glhv.org.au/ files/PrivateLives2Report.pdf.

Lessig Lawrence 1999, Code and Other Laws of Cyberspace, New York: Basic Books.

Lewandowski Piotr, Kobylska Joanna 2011, „Wpływ Internetu na relacje w grupie osób homoseksualnych w Toruniu", Nowe Media, No. 3, available at: http://apcz.pl/czasopisma/index.php/Nowe_Media/article/view/NM.2012.010/218

Lewis George H. 1990, “Community through Exclusion and Illusion: The Creation of Social Worlds in an American Shopping Mall", Journal of Popular Culture, No. 24.

Light Ben, Fletcher Gordon, Adam Alison 2008, “Gay Men, Gaydar and the Commodification of Difference", Information Technology and People, No. 21(3).

Livingstone Sonia M. 2008, “Taking Risky Opportunities in Youthful Content Creation: Teenagers' Use of Social Networking Sites for Intimacy, Privacy and Selfexpression", New Media and Society, No. 10(3).

McIntosh Wayne, Harwood Paul 2002, “The Internet and America's Changing Sense of Community", The Good Society, No. 11(3), available at: http://muse.jhu.edu/journals/ good_society/toc/gso11.3.html

McKenna Katelyn Y.A., Bargh John 1998, “Coming Out in the Age of the Internet: Identity 'Demarginalization' through Virtual Group Participation", Journal of Personality and Social Psychology, No. 75.

Morahan-Martin Janet 1999, "The Relationship Between Loneliness and Internet Use and Abuse", Cyber Psychology and Behavior, No. 2. 
Mowlabocus Sharif 2010, Gaydar Culture: Gay Men, Technology and Embodiment in the Digital Age, Surrey UK: Ashgate.

Nakamura Lisa 2002, Menu-Driven Identities: Making Race Happen Online, [in:] A Review of Cybertypes: Race, Ethnicity, and Identity on the Internet, New York: Routledge.

National LGBTI Health Alliance 2010, Suicide and LGBTI People (Information Sheet), available at: http://www.lgbthealth.org.au/briefingpapers

Oliwa Radosław 2012, Z szafy do ramówki, Sytuacja społeczna osób LGBT. Raport za lata 2010 i 2011, eds. M. Makuchowska i M. Pawlęga, Warsaw: Kampania Przeciwko Homofobii.

Parks Malcolm R., Floyd Kory 1996, "Making Friends in Cyberspace”, Journal of Computer-Mediated Communication, No. 1(4), available at: http://jcmc.indiana.edu/vol1/issue4/ parks.html

Prost Antoine, Ariès Phillippe, Vincent Gerard 1991, A History of Private Life: Riddles of Identity in Modern Times, Cambridge (MA): Harvard University Press.

Quercia Daniele, Las Diego, João Casas, Pesce Paulo, Stillwell David, Kosinski Michal, Almeida Virgilio, Crowcroft John 2012, Facebook and Privacy: The Balancing Act of Personality, Gender and Relationship Currency, [in:] Proceeding of the Sixth International AAAI Conference on Weblogs and Social Media, available at: http://aaai.org/ocs/index.php/ ICWSM/ICWSM12/paper/view/4613.

Schlenker Barry 1980, Impression Management: The Self-Concept, Social Identity, and Interpersonal Relations, Monterey (CA): Brooks/Cole.

Schmidt Kris 2011, “Gay 'Dating' Online: A User's Guide”, Popingay, available at: http:// popingay.com/post/2818824999/gaydating-online-a-users-guide

Sinfield Adam 1998, Gay and After, London: Serpent's Tail.

Sveningsson Elm M. 2009, How Do Various Notions of Privacy Influence Decisions in Qualitative Internet Research?, [in:] Internet Inquiry: Conversations about Method, eds. N. Baym, A. Markham, New York: Sage.

Thornton Sarah 1996, Club Cultures: Music, Media, and Subcultural Capital, Hanover: University Press of New England.

Tomasik, Krzysztof (2012), Gejerel. Mniejszości seksualne w PRL-u, Warsaw: Wydawnictwo Krytyka Polityczna.

Tyler Tom R. 2002, "Is the Internet Changing Social Life? It Seems the More Things Change, the More They Stay the Same", Journal of Social Issues, No. 58(1). 